\title{
Ethical Challenges in the Teaching of Improvisation for Psychologists' Communication
}

\author{
Olga B. Temezhnikova ${ }^{a^{*}}$, Takhir Yu. Bazarov ${ }^{\mathrm{b}}$ \\ a Academy of Public Administration, Moscow, Russia \\ ${ }^{\mathrm{b}}$ Lomonosov Moscow State University, Moscow, Russia \\ *Corresponding author. E-mail: olgatemezhnikova@mail.ru
}

Background. In the last few decades, the ethical issues in psychological research have gained considerable attention. In our study we discuss training of psychologists from the ethical point of view.

Objective. 1) To develop communication skills with the help of improvisation in a specially designed training program. 2) To uncover the role of ethical questions about the morality of risk-benefit assessment and justification for the conduct of research, selection of a suitable target population, informed consent, and evaluation of our results.

Design. Psychology students are required to develop communication skills that they will need in their future profession. The participants ( 70 psychology students) were asked to improvise following the three-stage procedure we designed. We describe all the stages of our training program and how the ethical norms contribute to our work. We discuss the ethical norms and rules in the first and third stages of our training session.

Results. We faced several ethical issues with risk-benefit assessment and justification of the conduct of the research. On the one hand, training causes anxiety, putting participants in uncomfortable situations; on the other, this corresponds precisely to the objectives of our work, posing an ethical dilemma. We looked for ways to create more comfortable conditions without jeopardizing the objectives of our study. We introduced concerns about the interpretation of an improviser's work. The improvisers told stories that did not always correspond to reality, which confused the other participants. Discussing this point from an ethical position led us to a deeper understanding of improvisation and led to certain modification in our design of the training program.

Conclusion. We consider improvisation a creative process which helps one to adapt to new, uncomfortable situations. Here we show that based on ethical standards and rules, we could properly organize our training and comprehensively review the learning and improvisation process.

(C) Russian Psychological Society, 2020

http://psychologyinrussia.com

Keywords:

improvisation, communication, educational training, ethical dilemmas, ethical standards 


\section{Introduction}

Huge advances in technology, novel challenges, and more and more complicated research have brought ethics to prominence in scientific psychology. Ethics is defined as a moral philosophy or code of morals practiced by a person or group of people (yourdictionary.com). In other words, ethics verbalizes what is considered good or bad, moral or immoral in a society at a given period of time. Although ethics in the narrow sense has been discussed and applied in medicine and biomedical research for centuries, ethics in the general sense and as applied to psychology is a concept of the 20th century (Dilman, 2005; Luegenbiehl \& Clancy, 2017; Mason et al., 2019; Spencer-Oatey \& Xing, 2019).

Although seemingly clear-cut, it still has certain areas requiring further conceptualization and rigorous research, with a particular focus on applied issues of psychology studies today. The basic principles of research ethics are three: (a) minimizing the risk of harm; (b) obtaining informed consent; and (c) protecting anonymity and confidentiality (Laerd Dissertation, n.d.; Artal and Rubenfeld, 2017; Grech, 2018).

The importance of ethics is supported by numerous articles dealing with medical practice or interaction with special groups of respondents. Thus, articles on cancer patients, newborns, and experimental studies of humans and animals emphasize the necessity to rely on ethical norms and rules, each time checking our actions in terms of the balance between benefits and harm, observing the boundaries of autonomy, and providing the requested information to all the participants in full (Harper et al., 2018; Buzdar and Hoover, 2017; Houdayer et al., 2019). The research tradition both abroad and here in Russia rests on already established milestones in medical studies and biological research.

The legacy of World War II triggered broad research on war veterans and other civilians finally leading to understanding of the need for guiding principles for investigating the human (Schuler, 2013). The first document designed to regulate the professional behavior of psychologists was the Code of Ethics of the American Psychological Association, which was adopted in 1953 (American Psychological Association, n.d.).

In Russia, psychological research has long followed the principles formulated by bioethics committees and the common sense intrinsic to the Russian school of psychology. Some issues were already formulated by B.S. Bratus' (1998). However it was not until the 21 st century that special attention was paid to ethics in psychology as a separate area (Bratus', 2019; Shaboltas, n.d.).

The Code of Ethics of the Russian Psychological Society was adopted in 2012 at the Fifth Congress of the Russian Psychological Society (Russian Psychological Society, 2012). It is based on the Constitution of the Russian Federation and reflects a wide palette of a psychologist's work. Yet, at the legislative level, this document has little power; it serves for self-regulation within the community rather than for protecting psychologists and their patients.

At the First International Conference on Ethics in Psychological Counseling and Psychotherapy in 2017, in Moscow, various aspects of ethical issues faced by counseling psychologists and psychotherapists were discussed, and a book of reports and articles from the conference was published (Kiselnikova et al., 2019). 
The field of psychological research in Russia is regulated, yet quite a number of questions still arise and require a balanced approach. Multidisciplinary approaches, with philosophy serving as the foundation, could be useful in this field. One of the seminal works is the book Would you kill the fat man? (Edmonds, 2015), where David Edmonds outlines ethical problems, providing a comprehensive view of the classic "trolley problem" in ethics, while analyzing many ethical theories and how each would respond to it. The book Justice: What's the right thing to do?, by Michael Sandel (Sandel, 2010) argues that justice is more important than being autonomous. Sandel quotes Alasdair MacIntyre and his characterization of humans as "storytelling beings" who live their lives with narrative quests. MacIntyre's bestknown book, After virtue (MacIntyre, 2016) is the product of a long-term ethical project. It diagnoses contemporary society as a "culture of emotivism", where moral language is used pragmatically to manipulate attitudes, choices, and decisions, so that contemporary moral culture is a theater of illusions with objective moral rhetoric masking arbitrary choices. MacIntyre followed his seminal work with two books examining the role that traditions play in judgments about truth and falsity, Whose justice? Which rationality? (MacIntyre, 2017) and Three rival versions of moral enquiry (MacIntyre, 2006). MacIntyre's next major work, Dependent rational animals: Why human beings need the virtues, investigates the social needs and social debts of human agents, and the role that a community plays in the formation of an independent practical reason (MacIntyre, 2006) .

However, the philosophical constructions, notwithstanding their profound insights and practical validity, are still abstract models, lacking the scope for numerous minor cases loaded with emotion and unresolved tensions.

In modern fiction writing, over the past decade quite a few books have addressed important ethical issues within the framework of the putative challenges of the 21 century. Kazuo Ishiguro's novels frequently grapple with the importance of the individual within the confines of society. Over the years returning to his novel Never let me go (Ishiguro, 2006) makes one think about the possible ethical limits for a man desiring to change nature, the existence of the soul, and whether all means are good for solving global human problems.

The ethical issues are a topic for many publications and in each new decade new questions are debated (Asmolov, 2016; Koonrungsesomboon et al., 2016; Kostis et al., 2018; Leontiev, 2013).

In our study we focus on the major ethical issues arising in purely scholarly research dealing with normal people in the educational context, when no ethical problems would be expected to arise at all. Still, quite a few issues appear upon closer inspection. In the following sections we address risk-benefit assessment and justification of the conduct of research, selection of a suitable target population, and informed consent in the context of our work.

\section{Methods}

Setting the goals for developing improvisation skills, we need both to use existing training exercises and to create new ones. Guided by the Code of Ethics of the Russian Psychological Society (Russian Psychological Society, 2012), we are aware that we must: 
1. Recognize the value and dignity of students and respect their individual, cultural, and role differences, including origin, social status, gender, age, sexual orientation, and physical disability. The participants should also be aware of their prejudices and stereotypes of perception and especially carefully monitor how these can affect the learning process.

2. Promote self-development and self-awareness of students so that they learn how to integrate personal discoveries and practice.

3. Be responsible for respecting the existing personal boundaries.

4. Recognize the personal life experience and personality of students.

5. Follow the progress of students' work and be ready to report to students and colleagues about what the researchers/teachers are doing and why.

6. Comply with the rules on confidentiality, which stipulate the responsibility of both the trainer and the students.

7. Provide students with the opportunity to discuss and evaluate the experience gained during the training individually and/or in groups, at least once during the training program.

Keeping these rules in mind, we further discus the organization of research on improvisation within the educational setting and the difficulties we faced designing the experiment, which had not only a scientific but also a training purpose. Since we had to videotape our training sessions to be able to further apply qualitative research methods, we requested the written consent of the participants.

Conducting the training sessions requires the mentors to create an atmosphere that includes all participants, to develop an action plan, and most importantly, to observe the personal boundaries of the participants, creating a safe working environment. In other words, to create an ethically balanced environment.

During our training session we created an unexpected communicative situation to develop communicative skills and to single out and study the significant skills encouraging improvisation. We examined the improvisational behavior of students through training sessions that included three stages: the preparatory stage, the main stage, and the analysis.

\section{Participants}

Our training is educational; its participants are 70 students from 19 to 22 years old. It was conducted at the Department of Psychology at Lomonosov Moscow State University, during a course on "Social Psychology of Negotiation", and at the Psychology Department of the Academy of Public Administration within the framework of "Communication Psychology".

\section{Procedure}

The training session comprised two lessons; it was technically complicated and demanded close attention to organizational details.

Much attention is paid to the preparatory phase, which accounts for a third of all the time, and preparation is also expected outside the classroom, which usually takes approximately one week until the next lesson. 
During the first stage, we present the full picture and the rules of behavior. We talk about the improvisation process from different angles, so that the participants get acquainted with this phenomenon from the theoretical point of view. We single out that we will work with developing communication skills. During the next lesson, we write down the rules according to which we plan to work during the main stage of the training and point out the following principles: voluntary participation, activity, confidentiality, respect for each other, actual communication (here and now), and competent feedback. We discuss these rules and add some if the students consider them necessary.

The procedure was approved by the Board of Ethics, Department of Psychology, Lomonosov Moscow State University.

Then the participants were shown Emilia Muller, a short film directed by Yvon Marciano shot in 1993. The plot is based on the improvising game of an actress. She came in for an audition and after a few general questions, they asked her to speak about the contents of her handbag. The intrigue was revealed at the end of the video, when it became clear that the actress was actually talking about the handbag belonging to the studio worker, not to herself. Thus, she managed to improvise in a highly unexpected situation. We asked them to prepare for the next class, as we were planning to role-play a similar story. We asked the participants to prepare their own bags, including small handbags, backpacks and others for the experiment beforehand: As the content of the bags will be displayed in front of all the participants, it should include only objects the participants are prepared to disclose before the audience. We asked their consent to videotape the improviser's work, which was to speak about the objects in the bag as if they belonged to him/her. The task of the analysts - the other members of the student team - was expert estimation of the videos.

For any research to be ethical, the researcher must have informed consent from the participants. The "informed" part of this ethical principle is the most important part. We warn the participants that their improvisation will be recorded, which implies a written consent.

The main stage was the training and the improvisation event. It comprises a warm-up exercise and the main stage. Let us briefly describe it here. Our participants gave their bags to us to attach a number to each of them. With the first exercise, we divided the participants into four groups. They chose one improviser within each group, while the others became expert analysts. The improviser picked a number and was given the corresponding bag, started taking objects out of it and speaking about them as if they belonged to him/her. Representatives of all groups played the role of an improviser. The exercise culminated in a feedback session in which the participants shared their impressions, thoughts, feelings, and comments. This feedback has a number of purposes. First, it aims to ensure that none of the participants have been harmed or made to feel uncomfortable in any way by the study. Second, it aims to make sure that the researchers have informed consent. Third, it allows the participants an opportunity to remove their results from the study if they felt insecure. Finally, it allows the participants to ask any questions about the study to make sure they fully understand its content and the purpose. 


\section{Results}

Analyzing the results of the training, we had the following difficulties. For heuristic purposes, we could divide them into those connected with the form and those connected with the content of the procedure. We will discuss the organization questions first.

How could the training be organized more effectively, observing personal autonomy and boundaries? The role-play required the participants to act in an unexpected situation, improvising while demonstrating their communication skills. From this point of view, the result was positive. But from the point of view of organizing the training, we had the following questions or ethical dilemmas. Could we achieve better results in the training of improvisation skills if we did not warn participants about the upcoming exercises and ask them to prepare? In particular, to prepare their bags? They put into their bags only things they were prepared to display to the large audience. However, we expected that the result of the training would have been better if we had not asked them to do so. It would have created a tense atmosphere, yet it would have stimulated improvisation even more and thus forced the development of communicative skills. Therefore, the outcome would have been better, while the experience would have been more stressful. Still, one cannot neglect the ethical questions in this respect. By improving one aspect, we would violate the ethical norms and we cannot rule out the possibility of harming some people. The following questions arise: How much can we violate personal boundaries by tightening up on the rules of training and achieving better results in improving the students' skills? For growth and personal development, the discomfort situation must be optimal so that there is a zone of proximal development, as this is an opportunity to learn new things with the help of a teacher and not to be overwhelmingly stressed.

Having conducted a series of such training programs, we would like to remove the task of preparing the bags for the next lesson done by the participants themselves. We intend to use tote bags thanks to their simplicity, spaciousness, and rectangular shape. These bags are convenient for many tasks, they are often distributed to participants at scientific conferences, and there are plenty of them ready at hand. Each participant would be supplied with a certain number of items, placing everyone on an equal footing. The main finding is that the improvisation process is at the right balance between the optimal level of anxiety and a good level of communication skills.

\section{Discussion}

Overall, we conducted our classes in accordance with the norms of the Code of Ethics of the Russian Psychological Society. All the participants included in our study discussed and agreed to the rules we devised. Discussing on a case by case basis, rather than presenting the already established rules, is critical for organizing the training session. Training, even when clearly structured and subordinated to a rigid plan, is a creative process, possible only if the interaction is open. Then creativity will become joint, and the synergy effect will be powerful. The presenter needs to solicit a joint discussion of the principles and values of the participants at the preliminary meeting. 
We used a set of exercises we had developed to teach communication skills, to be further explored in improvisation. Using non-standard formats makes it possible to create a qualitatively different level for development. This atmosphere also markedly enhances emotional involvement in the process.

However, the level of the students needs to be taken into account. If the format is too unexpected for the level of preparation of the participants, the training may have the exact opposite effect, turning people off. It is important to choose the right target audience and balance the stress and outcome.

The participants in our training were psychology students who have many practical classes and workshops during their education. The students are required to develop communication skills that they will all need in their future profession. Thus, they represent a good group for the training program, both to practice communication through improvisation and to study these processes. We faced several ethical issues with risk-benefit assessment and justification of the conduct of the research. We intentionally placed subjects in an unexpected communicative situation to create the conditions for improvisation. On the one hand, this causes anxiety, putting participants in an uncomfortable situation; on the other, it corresponds precisely to the goals of our work, presenting an ethical dilemma. Improvisation in communication means acting in unexpected conditions. It was important for us to ensure that the unexpected situation we created was experienced by the participants as an optimal one for training.

In the future, we plan to change the training at the preparation stage, in order to create more comfortable conditions for the participants, without jeopardizing the objectives of our study. We believe that irrespective of the training needs, goals, and efficiency, the participants' comfort and respect for personal boundaries remain of utmost importance for planning and designing any kind of training session or master class.

Some studies require that the participants be deceived in some way to achieve the study's goals and have reliable results. Deception includes: misleading the participants in any way and the use of stooges or confederates. But this is against the ethical standards set by the Russian Psychological Society. Deception is also unfavorable and sometimes even impossible in a training session, as it would impede the development of the necessary skills and destroy the comfortable atmosphere.

This is an important point, directly related to the ethical challenges in psychological practice. It is particularly the interpretation of results in terms of ethical standards and values that is difficult and calls for greater consideration and accuracy in contemporary settings.

Further questions arise about interpreting the results. It turned out that the simple process of evaluating the videos raised a number of ethical problems. These were discussed after the improvisation. An overview of the most frequent and pressing questions is presented below. This discussion was an important outcome of our training as it provided valuable feedback initiated by the participants, that has to be discussed.

Many of our participants, playing the role of the observers, wondered if it wouldn't turn out that a good, natural liar gives a better impression of himself by completing the task better than others. 
Where is the line between lies and fantasy?

What are limits of fantasy?

How to treat modern Munchausens?

Munchausen (Raspe et al., 2012) was a trickster of the Enlightenment, and like any trickster, he was highly ambivalent, negative and positive at the same time. As a rule, the trickster sets the task of changing the game, the situation and life, and does not act with malicious intent. It is not the game of life itself, but the process that is important for the trickster. On the one hand, he would seem to reject rationality by telling fables. He takes pleasure in penetrating the fabric of reality, opening up a rich palette of ways to interpret it. On the other hand, all of his fables have a clear rational or, more often, quasi-rational explanation.

In world literature, an example is a character created by the Swedish writer Astrid Lindgren, the world-famous Karlsson (Lindgren, 2008). Karlsson creates his own world, the world of a game, construes the reality that would help the boy grow, develop, and become an adult. Another character, sometimes irritating, sometimes arousing admiration, is Ostap Bender (Il'f \& Petrov, 2011). He is one of the most popular heroes of the picaresque novel in Russian literature, bringing together two worlds: reality and fantasy.

According to a definition of lies by Aldert Vrij (Vrij, 2008), "A lie is a successful or unsuccessful deliberate attempt, made without warning, to form another person's belief that the communicator considers incorrect". In his scientific articles, the author and colleagues consider various aspects of lies in verbal and non-verbal contexts (Leal et al., 2018).

According to recent studies, a false statement is usually filled with many details, in contrast to truthfully presented information. Expressions such as "sweet-talking" or "honey- tongued" imply a certain self-interest. A ridiculous story written in 1960 for children, "Fantazery", is an interesting illustration of this difference. It is about two boys who told each other all sorts of tales, competing over who would be better at lying (Nosov, 2010). A third boy sat on the bench facing them. He told how he had really deceived his mother by eating half a can of jam and blaming his sister for it. In the example, N.N. Nosov introduced the idea that the main thing in all the fantasies of the two boys does not relate to a person as a means, a tool to achieve personal goals, or as an object, whereas the third boy used his lies to harm his sister and to escape punishment.

Following Kant, we turn to moral law, the "categorical imperative": "So act that you use humanity, in your own person as well as in the person of any other, always at the same time as an end, never merely as a means" (Dimmock, 2017).

If we perceive fantasy in art, music, dance, and theater as leading to the creation of an artistic image, as the ability to combine emotional and rational components, in communication the fantasy may lead to problems. This is because it is a complex process that includes at least three different processes: communication (exchange of information), interaction (exchange of actions), and social perception (perception and understanding of the partner), which directly depend on social trust (Psychology Wiki, n.d.). 
After all these profound discussions, we have come to the idea that the improvisation process has to be evaluated, including its general effect. In the final stage, the expert analysts, having watched the videos of students, were to evaluate the stress resistance, communicative skills, and spontaneity of the improviser and the general effect, with a 5-point expert estimation protocol. A high assessment of the overall impression of the improvisation of colleagues depended in many respects on the inherent coherence and congruence of the situation, rather than on the presumed success of the improviser.

Our task is to show that improvisation in communication is a creative process aiming at creating images and organizing them into a meaningful whole.

With the help of imagination, the real world is mastered creatively; the images created are determined not by credibility, but by the logic of what is happening. The imbalance between reality and fantasy in creativity leads either to copying the real world or to fantasy, and creating images is much more important than fitting them into reality. The rules guiding their creation belong to the domain of art and fiction and not to the domain of real world and linear logic. This should be also considered when exploring such complex processes as improvisation and communication.

\section{Conclusion}

In our study we explored the improvisation process and its relationship to communication. Improvisation involves freedom expression, which determines the openness of instructions for participants, and the inclusion of all participants. In order to achieve this, one must choose a form of performance that inspires the confidence of the audience and does not turn it off. But this in turn requires a clear definition of the goals of the work shared by each participant in the training program. Otherwise, we lose the structure and encounter difficulty in interpreting the results. We arrive at the conclusion that improvisation is a creative process which helps to adapt to a new situation.

When choosing the profession of a psychologist working in research, counseling, or therapy, we are faced with many ethical choices. Ethical rules and norms enter our lives, first through acquaintance with them, then via personal experience, and finally from analysis of situations. It seems to us that this process is endless. Based on international practice and our experience, we have proposed seven rules for conducting the training sessions. The ethical principles that underlie our current regulatory framework must be carefully considered and reflected in several regulatory documents.

A teacher's work requires looking for new methods of work with various kinds of audiences. Seminars and workshops are supposed to be highly interactive, which requires a constant search for new types of group work. In this search, we need to be able to embrace all the difficulties of this work in the context of ethical norms and rules. We believe these rules need to be adapted for each group. Any uncomfortable situation may impede the improvisation process; therefore, developing improvisation skills is a highly delicate task pertaining to personal boundaries that must be carefully observed. 


\section{References}

American Psychological Association (n.d.). Ethical principles of psychologists and code of conduct. Retrieved from https://www.apa.org/ethics/code/

Artal, R. \& Rubenfeld, S. (2017). Ethical issues in research. Best Practice \& Research Clinical Obstetrics \& Gynaecology, 43, 107-114. https://doi.org/10.1016/j.bpobgyn.2016.12.006

Asmolov, A.G. (2016). Psychology of modernity as a social situation of development: Challenges of uncertainty, complexity and diversity. Procedia - Social and Behavioral Sciences, 233, 27-34. https://doi.org/10.1016/j.sbspro.2016.10.122

Bratus' B.S. (2019). Anomalii lichnosti. Psikhologicheskii podkhod [Anomalies of the personality. A psychological approach]. Moscow: Nikeya.

Bratus' B.S. (1998). Psikhologiya i etika: opyt postroeniya diskussii [Psychology and ethics: Experience of discussion building]. Obshchaya psikhologiya: monografii i sborniki [General psychology: Monographs and anthologies]. Moscow: Bakhrakh-M.

Dilman, İ. (2005). The self, the soul and the psychology of good and evil. London, New York: Routledge.

Dimmock, M. (2017). Ethics for A-level. OPEN Book Publishers. Retrieved from https://books. openedition.org/obp/4420\#bodyftn7.

Edmonds, D. (2015). Would you kill the fat man? The trolley problem and what your answer tells us about right and wrong. Princeton, NJ: Princeton University Press.

Grech, V. (2018). WASP (Write a Scientific Paper): Ethical issues and data protection in research. Early Human Development, 124, 42-43. https://doi.org/10.1016/j.earlhumdev.2018.04.020

Harper, L., Herbst, K.W., \& Kalfa, N. (2018). Ethical issues in research: Human and animal experimentation. Journal of Pediatric Urology, 14, 286. https://doi.org/10.1016/j.jpurol.2017.10.019

Hoover, T.C. \& Buzdar, A. (2017). Ethical considerations in human subjects research, in Ethical Challenges in Oncology (pp. 145-157). Elsevier. https://doi.org/10.1016/B978-0-12-803831-4.00009-9

Houdayer, F., Putois, O., Babonneau, M.L., Chaumet, H., Joly, L., Juif ... Faivre, L. (2019). Secondary findings from next generation sequencing: Psychological and ethical issues. Family and patient perspectives. European Journal of Medical Genetics, 62, 103711. https://doi.org/10.1016/j. ejmg.2019.103711

Il'f, I. \& Petrov, E. (2011). The twelve chairs. A.O. Fisher (Trans.). Evanston, IL: Northwestern University Press. https://doi.org/10.2307/j.ctv4cbhbg

Ishiguro, K. (2006). Never let me go. New York: Vintage.

Kiselnikova, E., Kuminsky, E., Lavrova, V., \& Zemtsova (Eds.) (2019). I Mezhdunarodnaya konferentsiya po etike v psikhologicheskom konsul'tirovanii i psikhoterapii. Sbornik materialov [First International Conference on Ethics in Psychological Counseling and Psychotherapy. Anthology of materials]. Retrieved from https://www.pirao.ru/upload/iblock/369/sbornik_etika_2017.pdf

Koonrungsesomboon, N., Laothavorn, J., \& Karbwang, J. (2016). Ethical considerations and challenges in first-in-human research. Translational Research, 177, 6-18. https://doi.org/10.1016/j. trsl.2016.05.006

Kostis, P.C., Kafka, K.I., \& Petrakis, P.E. (2018). Cultural change and innovation performance. Journal of Business Research, 88, 306-313. https://doi.org/10.1016/j.jbusres.2017.12.010

Laerd Dissertation (n.d.), Principles of research ethics. http://dissertation.laerd.com/principles-ofresearch-ethics.php

Leal, S., Vrij, A., Deeb, H., \& Jupe, L. (2018). Using the model statement to elicit verbal differences between truth tellers and liars: The benefit of examining core and peripheral details. Journal of Applied Research in Memory and Cognition, 7, 610-617. https://doi.org/10.1016/j.jarmac.2018.07.001

Leontiev, D. (2013). Personal meaning: A challenge for psychology. Journal of Positive Psychology. 8, 459-470. https://doi.org/10.1080/17439760.2013.830767

Lindgren, A. (2008). S. Death (trans.). Karlson on the roof. Oxford University Press, Oxford.

Luegenbiehl, H.C. \& Clancy, R.F. (2017). Global engineering ethics. https://doi.org/10.1016/C2016-001056-2

MacIntyre, A.C. (2017). Whose justice? Which rationality? Notre Dame, IN: Univ. of Notre Dame Press. 
MacIntyre, A.C. (2016). After virtue: a study in moral theory. Notre Dame, IN: Univ. of Notre Dame Press.

MacIntyre, A.C. (2006). Dependent rational animals: Why human beings need the virtues. Chicago, IL: Open Court.

MacIntyre, A.C. (2006). Three rival versions of moral enquiry: Encyclopaedia, genealogy, and tradition. Gifford Lectures delivered at the University of Edinburgh in 1988. Notre Dame, IN: Univ. of Notre Dame Press.

Mason, M., Crossley, M., \& Bond, T. (2019). Changing modalities in international development and research in education: Conceptual and ethical issues. International Journal of Educational Development, 70, 102080. https://doi.org/10.1016/j.ijedudev.2019.102080

Nosov, N. (2010). Dreamer/Fantazery. Moscow: Makhaon.

Psychology Wiki (n.d.). Communication. https://psychology.wikia.org/wiki/Communication

Raspe, R.E., Strang, W., \& Clark, J.B. (Eds.) (2012). The travels and surprising adventures of Baron Munchausen. Brooklyn, NY: Melville House Pub.

Russian Psychological Society (2012). Code of Ethics of the Russian Psychological Society. http:// psyrus.ru/en/documents/code_ethics.php

Sandel, M.J. (2010). Justice: What's the right thing to do? New York: Farrar, Straus and Giroux. https:// doi.org/10.1037/e597132010-001

Schuler, H. (2013). Ethical problems in psychological research. Elsevier Science. Academic Press.

Shaboltas A. (n.d.). K obsuzhdeniyu proekta eticheskogo kodeksa rossiiskogo psikhologicheskogo obshchestva [Toward discussion of the project for an ethical code of the Russian Psychological Society]. Vestnik Sankt-Peterburgskogo universiteta, Psikhologiya.Pedagogika [Bulletin of St. Petersburg University. Psychology. Pedagogy]. 75-84.

Spencer-Oatey, H. \& Xing, J. (2019). Interdisciplinary perspectives on interpersonal relations and the evaluation process: Culture, norms, and the moral order. Journal of Pragmatics, 151, 141-154. https://doi.org/10.1016/j.pragma.2019.02.015

Vrij, A. (2008). Detecting lies and deceit: Pitfalls and opportunities. Chichester: Wiley.

Original manuscript received November 11, 2019

Revised manuscript accepted May 12, 2019

First published online June 25, 2020

To cite this article: Temezhnikova, O.B., Bazarov, T.Yu. (2020). Ethical Challenges in the Teaching of Improvisation for Psychologists' Communication. Psychology in Russia: State of the Art, 13(2), 154-164. DOI: 10.11621/pir.2020.0211 